\title{
Impact Anlysis of Bow Flap on LHA-1 Ship Airwake
}

\author{
Jinling Wang ${ }^{1,2, a}$, Guangwen Jiang ${ }^{1}$, Jun Shen ${ }^{1}$ and Chujun $\mathrm{Hu}^{1}$ \\ ${ }^{1}$ Systems Engineering Research Institute, CSSC, 100094 Beijing, People's Republic of China \\ ${ }^{2}$ Beihang University, 100191 Beijing, People's Republic of China
}

\begin{abstract}
The sharp $90^{\circ}$ corner of bow found on American Tarawa class general amphibious assault ship LHA-1 will produce large separated region in the airwake over the ship, and the turbulence in the separation region seriously affects the operation safety of the helicopter. In order to reduce the separation in bow region of the LHA-1, and optimize the helicopter operating environment, the numerical simulation method is used to study the influence of the bow flap on the airwake of LHA-1. The study results show that: the ANSYS $k-\varepsilon$ two equation model based on the hybrid grid can be used to predict the steady-state characteristics of the ship airwake; the bow flap can improve the flow field downwind of the flap installation position, and the impact range can cover two spots; in headwind, the optimal installation angle of the bow flap is $15^{\circ} \sim 25^{\circ}$. The research results of this paper can provide modification and improvement reference for the amphibious assault ship in-service and under construction, so as to achieve the purpose of optimizing the ship airwake, thereby improving the safety of helicopter landing process and extending the service life.
\end{abstract}

\section{Introduction}

The amphibious assault ship that is the helicopter carrier, is available for launch and recovery operations of the helicopter formation, while the launch and recovery of helicopters on ships, especially the recovery, has become a worldwide technical issue. Not only does the pilot have to track a target moving with multiple degrees of freedom, but one must also land the helicopter in the highly unsteady airwake of the various pieces comprising the ship superstructure. The airwake contains relatively small length scales which will pass through the rotor, being felt as vibrations, and larger length scales that will affect the performance of the rotor as well as the handling characteristics of the helicopter[1]. Therefore, it is of great significance to study the ship airwake characteristics and take measures to optimize and control the airwake environment.

At present, many scholars have made airwake optimization and control research on the rear flight deck ship with the hangar. In 2002, Kumar[2] conducted subscale wind tunnel experiments to assess the effectiveness of passive control involving a porous surface and cavity underneath for reducing the level of surface pressure fluctuations in reattaching flows, and it demonstrated the design can significantly reduce the peak surface pressure fluctuations in the reattachment zone, a maximum reduction of as much as 35\% has been observed; in 2003, Tai[3] modified the SFS ship configuration by adding a rounded bow section at the front end to avoid complete separation along the side walls,

\footnotetext{
${ }^{\mathrm{a}}$ Corresponding author : bellincssc16@163.com
} 
the concluding remarked that the complete separation along the hull surface is avoided; in 2005, Shafer[4] explored both active and passive flow control techniques on flow field improvement in the helicopter's final decent onto the flight deck, results show that it would cause a reduction in unsteadiness in the landing region of $6.6 \%$ at 0 degrees wind-over-deck (WOD) and $8.3 \%$ at 20 degrees WOD by injecting air through the porous surfaces; in 2010, Forrest[5] found that it can decrease the adverse pressure gradient and the turbulence at the hangar edge by installing a $30^{\circ}$ flap at the hangar edge of starboard side or applying a chamfer with an angle of $30^{\circ}$; in 2013 , the midshipman LaSalle[6] of the United States Naval Academy examined the effects of passive flow control techniques on the ship airwake of YP, and the investigation showed that the particular passive flow control fence produce a less favorable ship airwake for helicopter launch and recovery operations due to an increase in shear, turbulent kinetic energy density, and mixing within the helicopter landing region.

Different from the rear flight deck ship with the hangar, the amphibious assault ship has several landing spots on the straight flight deck, and the related research show that the flow separation of the bow edge will seriously affect the safety of the helicopter operating at the front spots of LHA-1. In order to reduce the separation zone of the sharp 90-degree corner found on LHA-1, Czerwiec and Polsky[7] investigated the effect of adding a $22.5^{\circ}$ downward-deflected flap to the bow. Results from the wind tunnel and CFD showed that the flap reduced the turbulence levels related to pilot workload and aircraft fatigue. While Czerwiec and Polsky only discussed the airwake characteristics with $22.5^{\circ}$ downward-deflected flap in headwind. This paper will continue research the relationship between flap mounting angle and the airwake characteristics in different wind angles.

\section{Simulation Method}

\subsection{Geometric Model and Grid Generation}

Figures 1 show the original LHA-1 (left) numerical model and the one with bow flap (right), respectively. For both original and the modified models, the cargo door and elevators are closed and the antennas are neglected. The LHA-1 flight deck has 10 landing spots shown in figure 2.

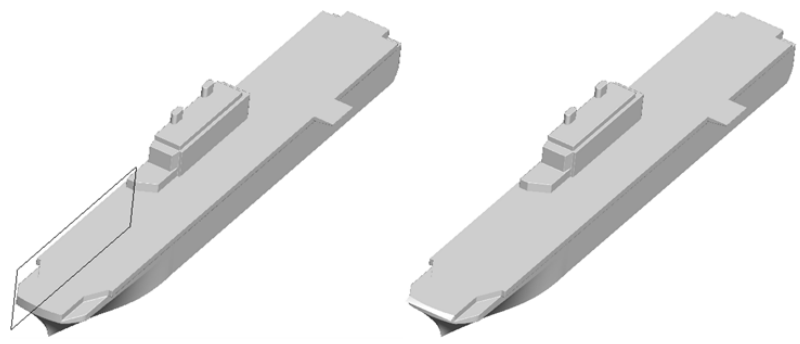

Figure 1. CFD model of LHA-1

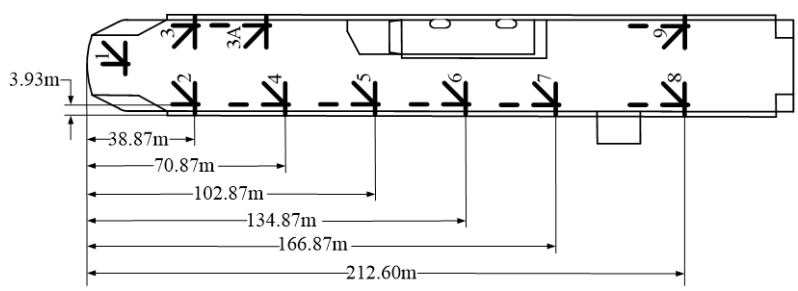

Figure 2. Location of LHA-1 landing spots 
Hybrid grids are generated using ANSYS ICEM, the height of the first boundary layer grid on the hull surface is set to $0.003 \mathrm{~m}$ to ensure that the dimensionless distance $y+$ is between 30 and 60 ; the maximum size of tetrahedral grid in the key area around the hull is $0.1 \mathrm{~m}$; the peripheral prismatic grid size is increasing exponentially from the periphery of the key area to the outer boundary. After verifying the grid independence, the number of grids used for numerical computation is $1.93 \times 10^{7}$, and the hull surface grids and the grids on the vertical section are shown in figure 3.

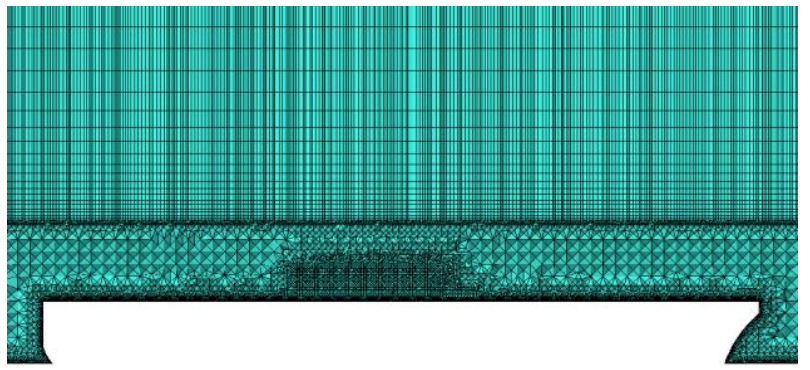

Figure 3. Distribution for different grids

\subsection{Numerical Method and Boundary Conditions}

The steady-state airwake of LHA-1 is simulated using commercial CFD solver ANSYS FLUENT, and the traditional Reynolds-average Navier-Stokes $k-\varepsilon$ two equation turbulence model is applied. At the inlet, free-stream condition of $20.6 \mathrm{~m} / \mathrm{s}$ is imposed; at the exit boundary, a pressure far field outlet is defined and viscous, no-slip conditions are applied to all surfaces of LHA-1; the flat stationary water surface is designated as frictionless surface.

\subsection{Simulation Conditions}

The CFD analysis is performed for a relative wind of $20.6 \mathrm{~m} / \mathrm{s}$ with a head wind and wind from the port bow (or relative wind angle $\theta$ ) of $15^{\circ}$. The simulation objects include the original LHA-1model and the model with bow flap. 12 different bow flap installation $\operatorname{angles}(\varphi$, the angle between the plane of the flap and the flight deck plane) are designed ranging from $5^{\circ}$ to $90^{\circ}$, and the original LHA-1 can been seen as the flap installation angle of $90^{\circ}$.

\section{CFD Analysis and Results}

\subsection{Validation of CFD with Wind Tunnel Results}

The experimental data to verify the numerical method of the CFD results come from NASA Ames Research Center's Fluid Mechanics Laboratory[8] using 1/48th-scale LHA-1model, and the tunnel's test section extends $2.1 \mathrm{~m}$ high by $3 \mathrm{~m}$ wide. Particle image velocimetry, 3 component velocity measurements were acquired at several landing spots along the ship deck for various wind speeds and ship yaw angles.

Figure 4 presents a comparison between CFD calculations and wind tunnel measured upwash distributions across the deck at the rotor tip-path-plane height of V-22 on the spot 2 and 4 . Both the variation trend and the upwash velocity value calculated by CFD are in agreement with the wind tunnel measured results for headwind and the green $15^{\circ}$ wind angle, which demonstrates that the eddy range and strength predicted by CFD are the same as the wind tunnel experimental results. The 
verification results proves that the ANSYS $k$ - $\varepsilon$ two equation model based on the hybrid grid can be used to predict the steady-state characteristics of the ship airwake.
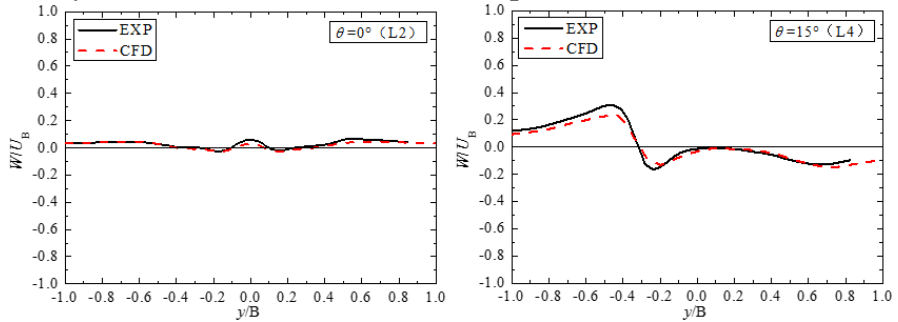

Figure 4. Comparison of CFD and experimental z-component velocity at spots 2 and 4

\subsection{The Influence of the Flap Installation Angle on LHA-1 Airwake}

Figure 5 provides the normalized vertical velocity contours predicted by CFD for the rotor disk of a UH-60 helicopter sitting on the flight deck in each of the three forward landing spots for 12 different flap installation angles $\varphi$ in headwind.

The contrast results show that: when $5^{\circ} \leqslant \varphi \leqslant 15^{\circ}$, as the $\varphi$ increasing, the vertical velocity gradient gradually decreases, and the flow field is even more uniform, the improvement effect of the helicopter landing area is more and more obvious, and the improvement effect of the airwake in the spot 1 is most obvious; when $\varphi=15^{\circ}$, the downwash of spot 1 disappears, and that in spot 2 and 3 are very weak; when $15^{\circ}<\varphi \leqslant 25^{\circ}$, the flow field is kept constant with the increase of $\varphi$ value; when $\varphi=30^{\circ}$, compared with which when $15^{\circ}<\varphi \leqslant 25^{\circ}$, the flow field in the spot 2 and 3 keep invariant, while the upwash region is smaller, and the uniformity of flow field becomes worse; when $30^{\circ}<\varphi \leqslant 90^{\circ}$, the improvement effect of the helicopter landing area is getting worse, and the velocity gradient is getting larger as the value of $\varphi$ increases.

The $\varphi$ interval in this paper is $5^{\circ}$, which is not enough to accurately capture the critical $\varphi$ that causing a change of the flow field. While it can be judged that the improvement of the flow is the best when the flap installation angle in the range of $15^{\circ}$ to $25^{\circ}$ according to the airwake variation trend of the LHA-1. It is observed from figure 5 that the flow field when $\varphi=22.5^{\circ}$ is the same with that when $\varphi=15^{\circ}, \varphi=20^{\circ}$ as well as $\varphi=25^{\circ}$. As it happens, Czerwiec and Polsky chose a flap installation angle which right locates in the range of the best installation angle for the improvement of the airwake.

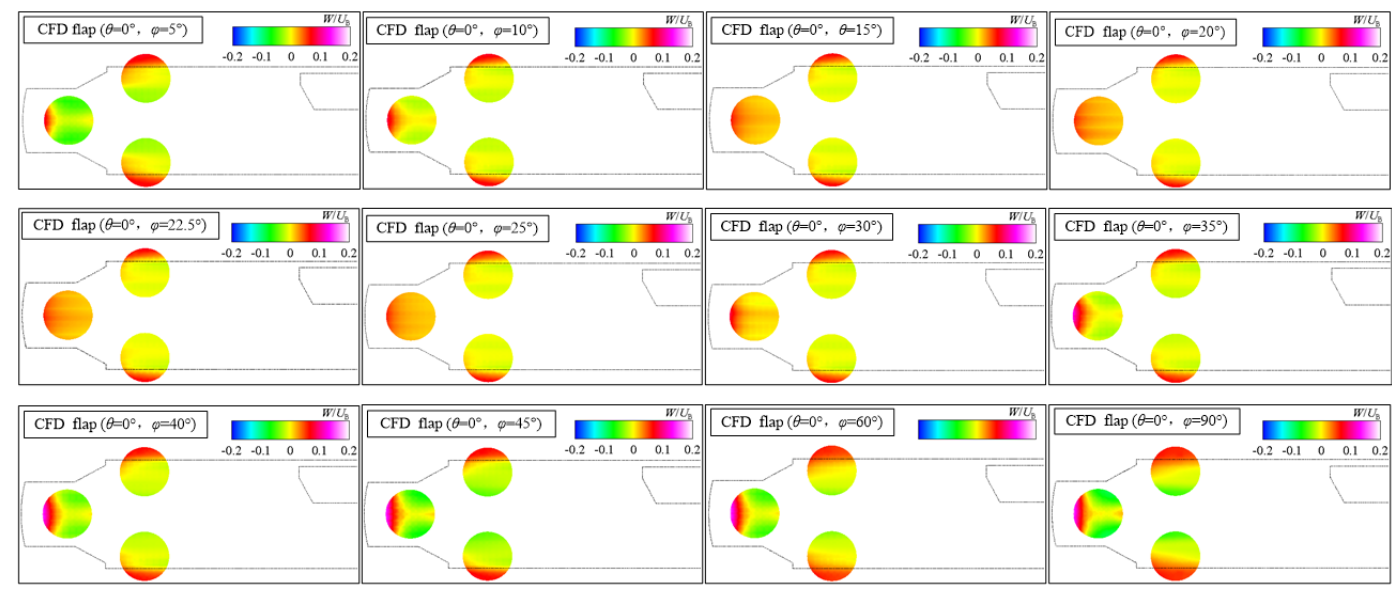

Figure 5. $z$-component velocity contours at the UH-60 rotor plane for LHA-1 with different bow flap angles in headwind 


\subsection{The $22.5^{\circ}$ Bow Flap Effects on ship airwake of LHA-1}

In this section, it continues to study the ship airwake characteristics of LHA-1 with and without $22.5^{\circ}$ bow flap. Figure 6 displays the vorticity isosurfaces on the flight deck of two models in headwind and red $15^{\circ}$ wind angle. For both WOD angles, the original LHA-1 model has larger coherent structures from the bow corner and the deck edges, the bow flap produces a significant reduction in the amount of vertical flow down the center of the flight deck. As a result, much of the bow and the center of the flight deck experience more uniform, steady flow for improved aircraft operation characteristics[7].

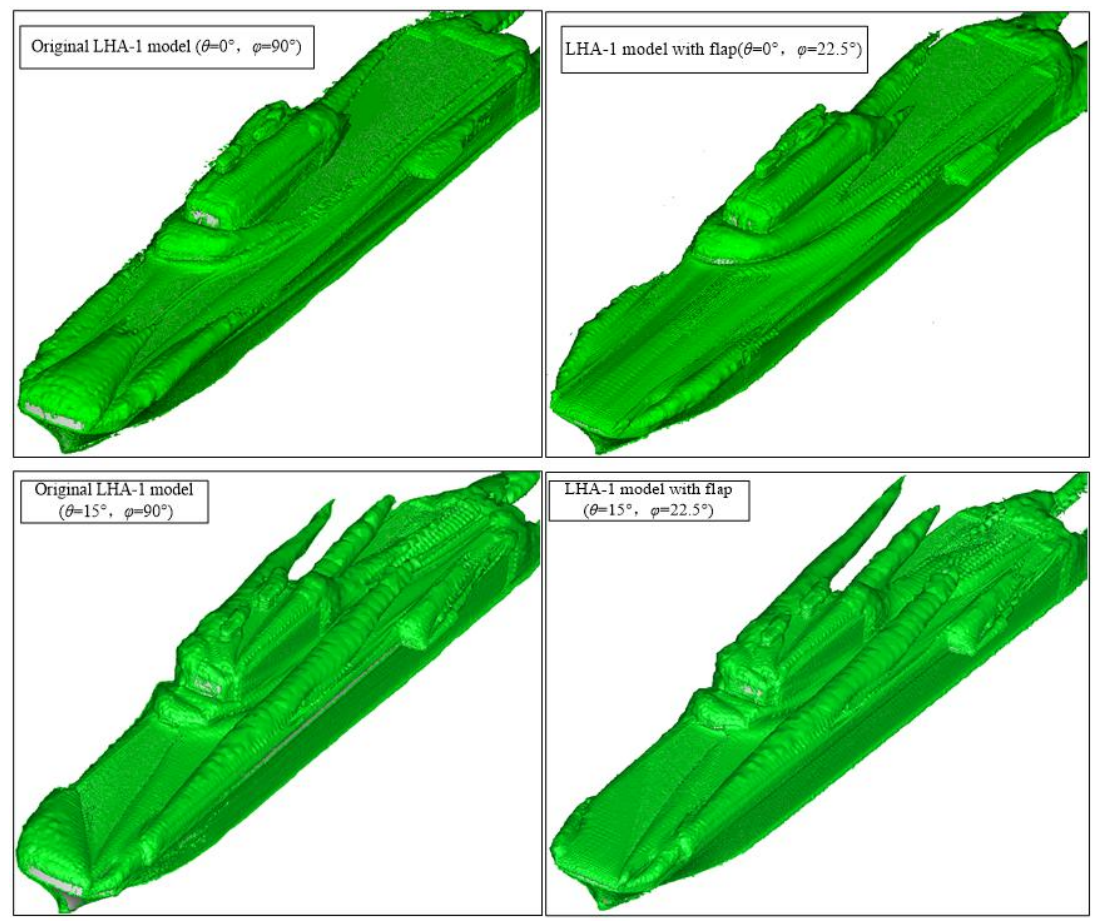

Figure 6. Iso-surface of vorticity of LHA-1 with and without bow flap in headwind and red $15^{\circ} \mathrm{WOD}$ angle

Figure 7 displays the pressure contour distribution over the bow for both CFD and wind tunnel results in headwind and red $15^{\circ}$, respectively. For original LHA-1 model, the large separated regions causing by the bow corner produce a low pressure, and the pressure in spot 1 is almost constant in headwind. For the modified LHA-1 model, the pressure increases gradually, and the pressure gradient decreases; especially for red $15^{\circ}$ wind angle, the low pressure zone in the port bow deck disappeared.

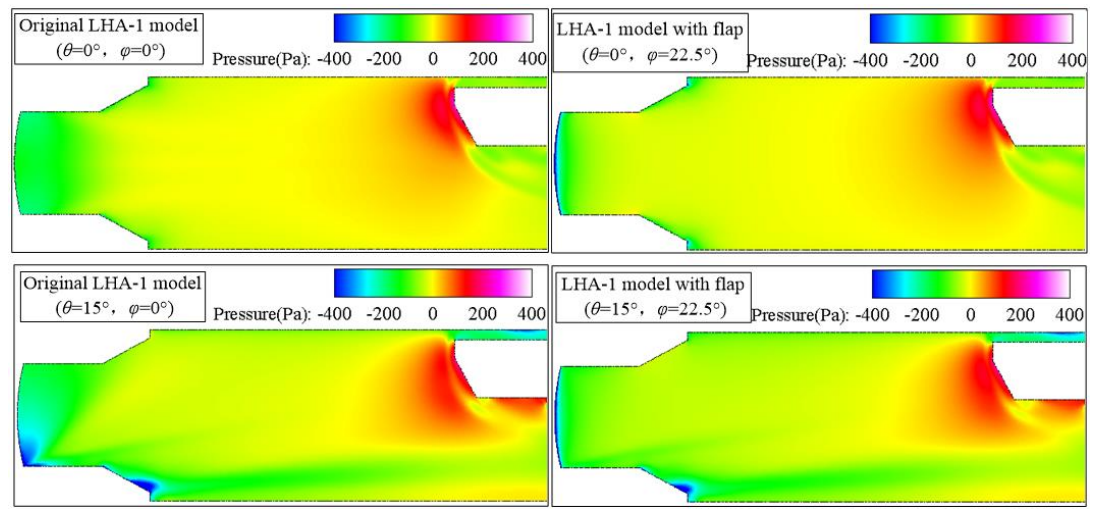

Figure 7. Pressure of flight deck surface for LHA-1 with and without bow flap in headwind and red $15^{\circ}$ 
Figure 8 supplies normalized vertical velocity contours for the rotor disk of UH-60 on three forward landing spots. The bow flap clearly produces much more uniform flow for spot 1 , and eliminates the downwash flow regions for three spots of headwind, and the downwash velocity in spot 2 reduced obviously for red $15^{\circ}$ wind angle. Combined with the calculation results in figure 7 , it can be found that the bow flap has obvious improvement effect on the downstream region of the flap installation position and its influence on the flow field can cover two spots.

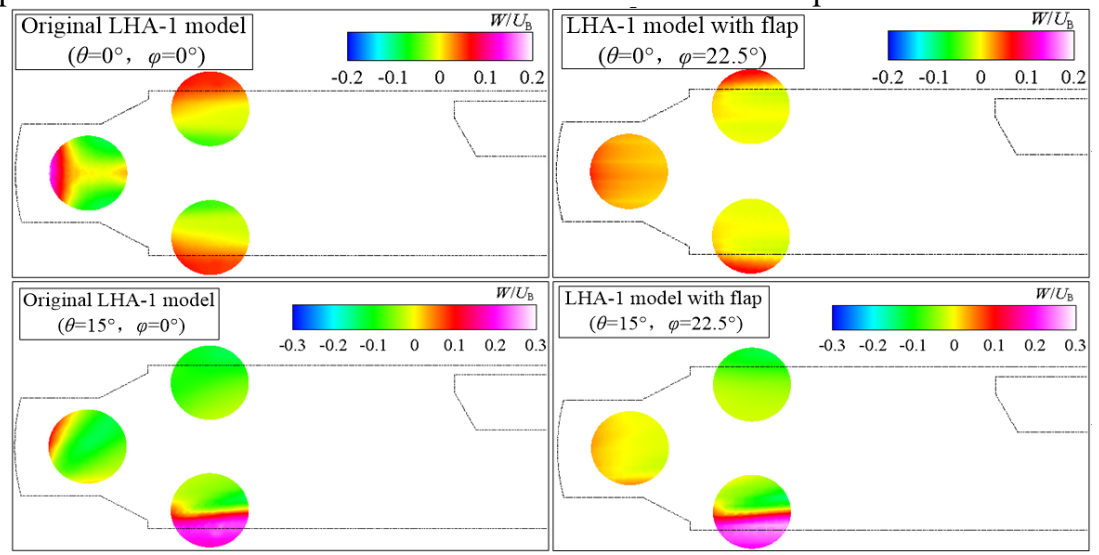

Figure 8. $z$-component velocity contours at the V-22 rotor plane for LHA-1 with/without bow flap in headwind and red $15^{\circ}$ WOD angle

\section{Conclusion}

The numerical simulation results of LHA-1 ship airwake with flap in different installation angles draw the following conclusions:

(1) The ANSYS $k-\varepsilon$ two equation model based on the hybrid grid can be used to predict the steadystate characteristics of the ship airwake;

(2) The bow flap can improve the flow field downwind of the flap installation position, and the impact range can cover two spots;

(3) In headwind, the optimal installation angle of the bow flap is located in range of $15^{\circ}$ to $25^{\circ}$.

This study shows that the bow flap with a specific installation angle will improve the uniformity of the ship bow airwake and reduce the flow separation. Future work will investigate more wind angles conditions, and the flap will be extended to the whole ship deck edge to further verify or extend the conclusion of this paper.

\section{References}

1. G. F. Syms. J. Wind, Eng. Ind. Aerodyn, 96, 1198(2008).

2. R. Kumar, R. Viswanath. Aer. J, 106, 673(2002).

3. T. C. Tai. NATO RTO Symp. Vort. Fl. High Angl. Att, 10(2003).

4. D. Shafer. Virginia Polytechnic Institute and State University, 95(2005).

5. J. Forrest, C. Kääriä, I. Owen. Am. Hel. Soc. 66th Ann. For. Techn. Displ, 15(2010).

6. LaSalle, N. Robert. Annapolis, 72(2013).

7. R. Czerwiec, S. Polsky. 22nd Appl. Aer. Conf. Exh, 2(2004).

8. G. Rajagopalan, D. Schaller, A. Wadcock, Yamauchi G, Heineck J, Silva M. 43th AIAA Aer. Sci. Meet. Exh, 2(2005). 